who were not diagnosed as definite migraine (group B) in fact showed the best response to ergotamine (Tables III and V). This was probably due to chance but it emphasizes the inadvisability of using the response to ergotamine as a criteria for diagnosis.

Ergotamine is widely accepted as the drug of choice in the treatment of migraine. Nevertheless, the danger of circular definitions, whereby migraine is a headache due to vasodilatation and ergotamine is highly specific because of its vasoconstrictor action, is obvious and has been stressed by Barrie et al. (1968). The possible fallacies in such definitions are already well documented in the case of ergotamine, which was introduced when migrainous headache was believed to be due to a spasm of the cranial arteries and when ergotamine was thought to act by producing arterial relaxation (Dunlop, 1969). It is now given for directly opposite reasons.

The absence of a beneficial effect of ergotamine over that of a placebo in this trial was surprising, and four possible reasons for this finding should be considered. Firstly, patients vary in their response to drugs, and this applies particularly in the treatment of migraine. It is difficult in a double-blind trial to adjust the dosage to each individual. In this trial a fairly standard regimen was followed so that attacks were treated with 2 or $3 \mathrm{mg}$. of ergotamine. In a double-blind sequential trial, Ostfeld (1961) found $5 \mathrm{mg}$. of oral ergotamine significantly more effective than a placebo. Some subjects in the present trial may have responded to higher doses but, as $22 \%$ had side-effects, a high dose would not seem appropriate for routine therapy.

Secondly, the women in this trial were identified in a community survey and are not highly selected individuals. It may be that only some migrainous patients respond to ergotamine. It should be stressed, however, that the subjects in this trial are representative of most women with migraine.

Thirdly, the swallowing of ergotamine tablets is considered to give less reliable results than if the drug is given by other routes. Oral administration, however, has the practical advantage that it can more conveniently be taken at what is thought to be the most effective time, early in the attack.
Sublingual administration is often recommended, but in a small controlled trial comparing ergotamine and a placebo no evidence of a beneficial effect was found (Crooks et al., 1964).

Finally, it may be relevant that over $80 \%$ of all ergotamine tablets prescribed in England and Wales in 1968 contained caffeine. Caffeine is thought to have a synergistic action with ergotamine but there seems little hard evidence for this general impression (Dunlop, 1969) and it may act by direct vasoconstriction of the cerebral blood vessels (Ritchie, 1965). Whatever the reasons for the results of this trial, it does focus attention on the difficulty of treating migraine. As nearly one in every five women aged 20 to 64 years in the original survey area had migraine (Waters and O'Connor, 1970) the need for further evaluation of therapy is obvious.

I thank Professor A. L. Cochrane, Director of the M.R.C. Epidemiology Unit, for advice and encouragement; Mrs. Gaynor Griffiths for assistance; and the subjects for their co-operation. The work was aided by a grant from the Migraine Trust and the tablets were supplied by Dr. E. R. Evans, of Sandoz Products Limited.

\section{REFERENCES}

Asher, R. (1948). Lancet, 2, 771.

Barrie, M. A., Fox, W. R., Weatherall, M., and Wilkinson, M. I. P. (1968). Quarterly fournal of Medicine, 37, 319.

Brazeau, P. (1965). In The Pharmacological Basis of Therapeutics, 3rd ed., edited by L. S. Goodman and A. Gilman, p. 878. New York, Macmillan.

Crooks, J., Stephen, S. A., and Brass, W. (1964). British Medical fournal, 1, 221.

Dunlop, D. (1969). In Background to Migraine: Second Migraine Symposium, edited by R. Smith, p. 72. London, Heinemann.

Friedman, A. P., and Merritt, H. H. (1959). Headache: Diagnosis and Treatment. Philadelphia, Davies.

McNemar, Q. (1947). Psychometrika, 12, 153.

Ostfeld, A. M. (1961). American fournal of Medical Science, 241, 192.

Ostfeld, A. M. (1963). Neurology (Minneapolis), 13, No. 3, Part 2, p.

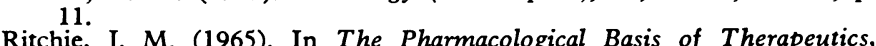
3rd ed., edited by L. S. Goodman and A. Gilman, p. 354. New York, Macmillan.

Waters, W. E. (1970). Headache, 9, 178.

Waters, W. E., and O'Connor,' P. J. (1970). In Background to Migraine: Third Migraine Symposium, edited by A. L. Cochrane. London, Heinemann. In Press

Wolff, H. G. (1963). Headache and Other Head Pain, 2nd ed. New York, Oxford University Press.

\title{
Comparative Trial of Serotonin Antagonists in the Management of Migraine
}

\author{
J. W. LANCE, ${ }^{*}$ M.D., M.R.C.P., F.R.A.C.P.; M. ANTHONY,† M.D., M.R.C.P., M.R.A.C.P. \\ B. SOMERVILLE, $\ddagger$ M.B., M.R.C.P., R.M.A.C.P.
}

British Medical fournal, 1970, 2, 327-330

Cummary: The effectiveness of five different serotonin antagonists in the prevention of migraine was compared in 290 patients followed for periods of up to three years. Methysergide 3-6 mg. daily was most effective, with $20 \%$ of treated patients becoming headache-free and a further $44 \%$ remaining more than "half improved." The corresponding figures for BC105 were $10 \%$ and $40 \%$, respectively.

The results with $\mathrm{BC} 105$ were significantly better than those with placebo $(P<0.02)$. The total improvement rates with methdilazine $(45 \%)$ and cyproheptadine $(43 \%)$ were better than those with placebo $(32 \%)$ but did not achieve statistical significance. A new preparation, methylergol carbamide maleate, which is chemically related to methysergide, did not give better results than placebo.

* Chairman, Division of Ncurology, the Prince Henry and Prince of Wales Hospitals, Sydney; Associate Professor of Medicine, University of New South Wales.

† Neurologist, the Prince Henry and Prince of Wales Hospitals, Sydney.

¥ Commonwealth Postgraduate Scholar and Sandoz Research Fellow in Neurology.

\section{Introduction}

When methysergide was first reported to be useful in the prevention of migraine (Sicuteri, 1959) the fact that it was a serotonin antagonist led to speculation that plasma serotonin may be increased during the migraine attack and be responsible for some of the symptoms of migraine. Subsequently Sicuteri, Testi, and Anselmi (1961) found that the major metabolite of serotonin, 5-hydroxyindoleacetic acid (5HIAA), was often increased during migraine headache. Thus it was surprising to find that the plasma serotonin level dropped sharply at the onset of migraine headache and remained low as long as the headache persisted (Curran, Hinterberger, and Lance, 1965). Anthony, Hinterberger, and Lance (1967) showed that the reduction of plasma serotonin to about $40 \%$ of its former level was specific for migraine headache and did not occur with the headache following pneumoencephalography, even when this was accompanied by vomiting. It has since been found that plasma serotonin is unaltered in cluster headache, and the change in migraine is produced by a serotonin-releasing factor in the plasma, which is present only at the time of headache (Anthony, Hinterberger, and Lance, 1969). 
Since serotonin is a potent constrictor of scalp arteries in man (Lance, Anthony, and Gonski, 1967), probably the fall of plasma serotonin permits the extracranial vasodilatation which is characteristic of migraine headache. In this case, how can antiserotonin agents exert any beneficial effect in the prophylaxis of migraine? Methysergide probably acts as a competitive antagonist to serotonin and potentiates the action of vasoconstrictor agents in the same manner as serotonin (Dalessio, Camp, Goodell, and Wolff, 1961; De La Lande, Cannell, and Waterson, 1966). The present hypothesis is that methysergide is responsible for the maintenance of extracranial vasoconstriction on occasions when plasma serotonin falls in migrainous subjects.

\section{Present Trial}

The present clinical trial started as a comparative assessment of the usefulness of methysergide and cyproheptadine in preventing migraine, but was widened to include other preparations which have shown serotonin antagonism in experimental studies. The preparations used in the trial were as follows:

(1) Methysergide (Deseril, Sansert).-Methysergide (1-methylD-lysergic acid butanolamide) was developed as one of a large group of semisynthetic ergot derivatives from the naturally occurring ergometrine. It was found to be four times more effective than lysergic acid diethylamide (L.S.D.) in antagonizing the effect of serotonin on the isolated rat uterus and in preventing oedema produced by serotonin in the rat's paw. It has weak antihistamine effects and no known activity against bradykinin. Methysergide is prepared as 1-mg. tablets in Australia and the U.K. and 2-mg. tablets (1.4 mg. base) in the U.S.A. About $60 \%$ of patients with frequent severe attacks of migraine are substantially improved by treatment with methysergide (Curran, Hinterberger, and Lance, 1967). The dosage used in this trial was 1-2 mg. three times daily.

(2) Cyproheptadine (Periactin).-Cyproheptadine (1-methyl4-(5-dibenzo-[a, e]-cycloheptatrienylidene)-piperidine hydrochloride has both antihistamine and antiserotonin properties. It has only about $5 \%$ of the antiserotonin activity on the isolated uterus as methysergide, but is 10 times more effective in protecting against a lethal dose of serotonin. Cyproheptadine relieved migraine in 18 out of 21 patients studied by Miller and Fishman (1961) and in 46 out of 100 patients by Curran and Lance (1964). The dose used in this trial was 4-8 $\mathrm{mg}$. three times daily.

(3) BC105.-This is a benzocycloheptathiophene derivative with a basic side-chain resembling that of cyproheptadine. It has the formula 4-[1-methylpiperidylidene-(4)]-9,10-dihydro-4H-benzo $[4,5]$ cyclohepta [1-2-b]-thiophene. BC105 is 300 times less active than methysergide in protecting against serotonin-induced oedema in the rat's paw, three times weaker in preventing contraction of the isolated rat uterus, but is 14 times more powerful than methysergide in protecting against a lethal dose of serotonin. $\mathrm{BC} 105$ is a stronger antihistamine agent than cyproheptadine and has no known bradykinin antagonism. Sicuteri, Franchi, and Del Bianco (1967) reported that $70 \%$ of patients with three or more migraine attacks each month were improved by therapy with BC105. The dosage used in this trial was $1.5-3 \mathrm{mg}$. three times daily.

(4) Methdilazine (Tacaryl, Dilosyn).-This is an N-substituted phenothiazine derivative. Its antihistamine action is four times that of promethazine, and its antiserotonin effect is about $10 \%$ that of L.S.D. when tested on smooth muscle in vitro, but is only $1 \%$ that of L.S.D. in protecting guinea-pigs against serotonin-induced asphyxial collapse (Lish, Albert, Peters, and Allen, 1960). It is about $4 \%$ as potent as L.S.D. in antagonizing oedema produced by serotonin in the rat's paw. Methdilazine inhibits the permeability changes resulting from the injection of bradykinin into human skin (Feher and Kalz, 1966). Because of its strong antihistamine and antibradykinin acivity it was thought to be worth a trial in the management of migraine, in spite of its relatively weak antiserotonin activity. Methdilazine was used in the form of 8-mg. tablets, 1-2 tablets morning and night.

(5) Methylergol Carbamide Maleate (Lysenyl).-This is a substituted amide of lysergic acid, N-D-6-methylisoergolenyl- diethylcarbamide, which is related chemically to methysergide. Lysenyl has about one-fifth the antiserotonin activity of methysergide when tested in the rat's paw. It has been reported from Czechoslovakia to be useful in the management of migraine. It was used in this clinical trial as tablets of $0.025 \mathrm{mg} ., 1-2$ tablets being given three times daily.

\section{Patients and Methods}

The trial included 290 patients who were referred to the neurological clinics of the hospitals over the past three years for migraine. Patients were admitted to the trial if their headaches were severe, episodic, associated with the usual migrainous features such as nausea, vomiting, or photophobia, and had recurred at least twice each month for the preceding six months. The headaches were not necessarily unilateral or accompanied by focal neurological symptoms-for example, fortification spectra, paraesthesiae, speech disturbance, vertigo, ataxia-provided that other criteria for the diagnosis of migrainous headache were present. Patients were excluded from the trial if they suffered from tension headaches which recurred with sufficient frequency or severity to confuse the recognition of migraine attacks. Of the 290 patients, 55 were male and 235 female. Headaches were consistently bilateral in 62 patients and predominantly unilateral in the remainder. Focal neurological symptoms accompanied the headache in $\mathbf{1 1 6}$ patients. The mean frequency of headache was 4.5 per month (range 2-12 per month).

The patients placed on placebo tablets were drawn from two double-blind trials conducted over this period (Anthony and Lance, 1968; Lance and Anthony, 1968). The trial was otherwise uncontrolled. Patients presenting to the clinic for the first time were placed on one or other form of interval medication, starting with the lower dose specified above. They were instructed to increase the dosage over three days to the maximum quoted, unless side-effects prevented them from doing so. Patients returned to the clinic at intervals of one month. They were then assessed as being headache-free, greater than half improved (half or less than half the previous frequency of headache), or unimproved. Reduction in severity of the headache was not usually considered because of the subjectivity of individual assessment. Patients who improved satisfactorily were then maintained on the appropriate medication. Those who did not respond were transferred to another form of treatment. The results were compiled separately for each medication when given as the first treatment and when given after an initial medication had failed. Any patient who was lost to follow-up or who abandoned the preparation because of side-effects was classified as unimproved.

\section{Results}

The assessment of patient response after one month of treatment with each preparation is shown in Table I. If only the response to the initial treatment given to the patient on first attending the clinic is considered, it is apparent that methysergide was significantly better than $\mathrm{BC} 105(\mathrm{P}<0.01)$ or placebo $(\mathrm{P}<0.001)$. The results with $\mathrm{BC} 105$ were also better than those with placebo $(P<0.02)$. The improvement rates with cyproheptadine and methdilazine, though better than with placebo, did not achieve statistical significance.

Patients who had failed to improve on the initial medication and were transferred to another form of treatment (Table I) were found to show little difference in their response to BC105, cyproheptadine, and methdilazine. These results cannot be analysed statistically because the sequence of medication was not controlled. During treatment with methysergide $20 \%$ of patients became free of headache, compared with $10 \%$ for $\mathrm{BC105}$ and methadilazine and $7.5 \%$ for cyproheptadine. In neither the initial nor the subsequent treatment groups did 
TABLE I

\begin{tabular}{|c|c|c|c|c|c|c|c|c|c|c|c|c|c|c|c|}
\hline & & & & & & & & & & \multirow{2}{*}{$\begin{array}{l}\text { Headache } \\
\text { Free }\end{array}$} & \multirow{2}{*}{$\begin{array}{c}\text { Half } \\
\text { Improved }\end{array}$} & \multirow{2}{*}{ No Change } & \multirow{2}{*}{ Abandoned } & \multicolumn{2}{|c|}{ Improved } \\
\hline & & & & & & & & & & & & & & No. & $\%$ \\
\hline \multirow[t]{2}{*}{ Placebo } & $\left\{\begin{array}{l}\text { Initial } \ldots \\
\text { Subsequent }\end{array}\right.$ & .. & $\because$ & . & $\begin{array}{l}. \\
\therefore\end{array}$ & $\because$ & $\begin{array}{l}\cdots \\
\cdots\end{array}$ & $\begin{array}{l}\cdots \\
\cdots \\
\end{array}$ & $\begin{array}{l}\cdots \\
\cdots \\
\end{array}$ & $\begin{array}{l}3 \\
1 \\
\end{array}$ & $\begin{array}{l}8 \\
4 \\
\end{array}$ & $\begin{array}{l}22 \\
10 \\
\end{array}$ & $\begin{array}{l}2 \\
0 \\
\end{array}$ & $\begin{array}{r}11 / 35 \\
5 / 15 \\
\end{array}$ & $\begin{array}{l}31 \\
33 \\
\end{array}$ \\
\hline & Total $\quad \ldots$ & . & .. & .. & .. & $\ldots$ & $\ldots$ & $\ldots$ & $\ldots$ & 4 & 12 & 32 & 2 & $16 / 50$ & 32 \\
\hline \multirow[t]{2}{*}{ Lysenyl } & $\left\{\begin{array}{l}\text { Initial } \ldots . . \\
\text { Subsequent }\end{array}\right.$ & . & $\because$. & .. & $\begin{array}{l}. \\
. \\
\end{array}$ & $\begin{array}{l}. \\
\cdots \\
\end{array}$ & $\because$ & 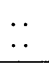 & $\because$. & $\begin{array}{l}2 \\
1 \\
\end{array}$ & $\begin{array}{l}8 \\
4 \\
\end{array}$ & $\begin{array}{l}14 \\
10 \\
\end{array}$ & $\begin{array}{l}4 \\
1 \\
\end{array}$ & $\begin{array}{r}10 / 28 \\
5 / 16 \\
\end{array}$ & $\begin{array}{l}36 \\
31 \\
\end{array}$ \\
\hline & Total $\ldots$ & . & .. & $\ldots$ &.. &. & .. & $\ldots$ & $\ldots$ & 3 & 12 & 24 & 5 & $15 / 44$ & 34 \\
\hline \multirow[t]{2}{*}{ Cyproheptadine } & $\left\{\begin{array}{l}\text { Initial ... } \\
\text { Subsequent }\end{array}\right.$ & $\begin{array}{l}\cdots \\
\cdots \\
\end{array}$ & $\begin{array}{l}. \\
\cdots\end{array}$ & $\begin{array}{l}\cdots \\
\cdots\end{array}$ & $\begin{array}{l}\ldots \\
\cdots\end{array}$ & $\begin{array}{l}\cdots \\
\cdots\end{array}$ & $\begin{array}{l}. \\
\therefore\end{array}$ & $\begin{array}{l}\cdots \\
\cdots\end{array}$ & $\begin{array}{l}. \\
\cdots\end{array}$ & $\begin{array}{l}5 \\
5\end{array}$ & $\begin{array}{l}19 \\
30\end{array}$ & $\begin{array}{l}30 \\
38\end{array}$ & $\begin{array}{l}7 \\
3\end{array}$ & $\begin{array}{l}24 / 61 \\
35 / 76\end{array}$ & $\begin{array}{l}40 \\
46\end{array}$ \\
\hline & Total $\quad$. & $\therefore$ & . & $\ldots$ & .. &. & . & $\cdots$ & $\ldots$ & 10 & 49 & 68 & 10 & $59 / 137$ & 43 \\
\hline \multirow[t]{2}{*}{ Methdilazine } & $\left\{\begin{array}{l}\text { Initial } \\
\text { Subsequent }\end{array}\right.$ & $\because$ & $\because$ & 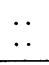 & . & $\because$ & $\because$ & 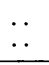 & $\begin{array}{l}\ldots \\
\cdots \\
\end{array}$ & $\begin{array}{l}4 \\
5 \\
\end{array}$ & $\begin{array}{l}17 \\
15 \\
\end{array}$ & $\begin{array}{l}29 \\
19 \\
\end{array}$ & $\begin{array}{l}1 \\
1\end{array}$ & $\begin{array}{l}21 / 51 \\
20 / 40 \\
\end{array}$ & $\begin{array}{l}41 \\
50 \\
\end{array}$ \\
\hline & Total & $\therefore$ & $\therefore$ & .. &.. & $\ldots$ & .. & $\ldots$ & .. & 9 & 32 & 48 & 2 & $41 / 91$ & 45 \\
\hline \multirow[t]{2}{*}{ BC105 } & $\left\{\begin{array}{l}\text { Initial } \ldots \\
\text { Subsequent }\end{array}\right.$ & 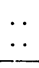 & $\because$ & $\begin{array}{l}. \\
\cdots\end{array}$ & $\begin{array}{l}\cdots \\
. \\
\end{array}$ & $\begin{array}{l}\because \\
. \\
\end{array}$ & $\begin{array}{l}. \\
.\end{array}$ & $\begin{array}{l}. \\
. \\
\end{array}$ & $\begin{array}{l}. \\
. \\
\end{array}$ & $\begin{array}{l}6 \\
4 \\
\end{array}$ & $\begin{array}{l}25 \\
17 \\
\end{array}$ & $\begin{array}{l}22 \\
27 \\
\end{array}$ & $\begin{array}{l}\mathbf{0} \\
\mathbf{2} \\
\end{array}$ & $\begin{array}{l}31 / 53 \\
21 / 50 \\
\end{array}$ & $\begin{array}{l}58 \\
42 \\
\end{array}$ \\
\hline & Total & . & . & . & .. & . & .. & . & .. & 10 & 42 & 49 & 2 & $52 / 103$ & 50 \\
\hline \multirow[t]{2}{*}{ Methysergide } & $\left\{\begin{array}{l}\text { Initial } \\
\text { Subsequent }\end{array}\right.$ & $\therefore$ & $\because$ & 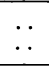 & $\begin{array}{l}\cdots \\
\cdots \\
\end{array}$ & $\begin{array}{l}\cdots \\
\cdots\end{array}$ & $\begin{array}{l}. \\
\therefore\end{array}$ & $\begin{array}{l}. \\
.\end{array}$ & $\begin{array}{l}\cdots \\
\cdots\end{array}$ & $\begin{array}{l}12 \\
19 \\
\end{array}$ & $\begin{array}{l}29 \\
36 \\
\end{array}$ & $\begin{array}{l}17 \\
23 \\
\end{array}$ & $\begin{array}{r}4 \\
11\end{array}$ & $\begin{array}{l}41 / 62 \\
55 / 89 \\
\end{array}$ & $\begin{array}{l}66 \\
62 \\
\end{array}$ \\
\hline & Total & . & . & . & . & . & .. & $\ldots$ & $\ldots$ & 31 & 65 & 40 & 15 & $96 / 151$ & 64 \\
\hline
\end{tabular}

Lysenyl give better results than placebo. The follow-up period for those patients who responded satisfactorily extends up to three years in the case of methysergide and cyproheptadine, to 12 months for $\mathrm{BC} 105$, and to eight months for methdilazine and Lysenyl. Relapses have occurred in three patients taking methysergide after three to six months, in five taking BC105 after two to six months, in five taking cyproheptadine after 2 to 12 months, and in one taking methdilazine after three months.

The commonest side-effects (Table II) with methysergide were muscle pains and cramps, coldness of the limbs, epigastric discomfort, and nausea. Similar symptoms were encoun-

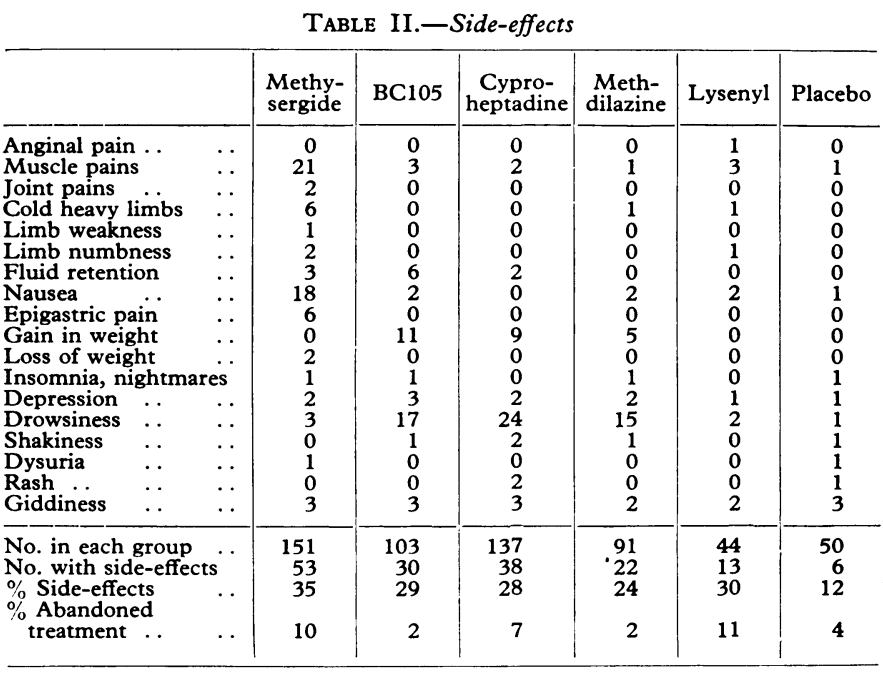

tered with Lysenyl, and one patient experienced a constricting chest pain, radiating to the left arm, on the second day of treatment, which did not return after stopping the drug. The side-effects of cyproheptadine, BC105, and methdilazine were very similar, drowsiness being by far the most common, with increased appetite, craving for sweets, and weight gain forming an important secondary group.

\section{Discussion}

Our results with methysergide and cyproheptadine resemble those of an earlier trial conducted in this clinic with a different group of patients (Curran and Lance, 1964), in which the improvement rate under treatment was $64 \%$ with methysergide, $46 \%$ with cyproheptadine, and $20 \%$ with placebo. When BC105 was originally submitted to a double-blind trial in this clinic, 12 out of 25 patients improved compared with 9 out of 25 given placebo, a difference which was not statistically significant. After the reports by Graham (1968) and Ryan (1968) on the efficacy of BC105 we decided to use the preparation to treat at least 100 patients. With larger numbers the results with $\mathrm{BC} 105$ now attain statistical significance, though the percentage improvement is little different from that of the original trial.

The improvement rate with methdilazine and cyproheptadine was consistently better than that with placebo. Since the placebo response in this trial was higher than in most trials conducted in this clinic, possibly both cyproheptadine and methdilazine would prove to be effective if separate double-blind trials were conducted with each preparation being evaluated against placebo. Our previous experience with cyproheptadine (Curran and Lance, 1964) suggests that this would be the case.

Clearly methysergide remains the most effective of the serotonin antagonists, but its widespread use has been discouraged by the frequency of side-effects, which prevent some $10 \%$ of patients from continuing treatment. Initial side-effects are minimized by giving a test dose of $1 \mathrm{mg}$., then increasing the dose gradually from $1 \mathrm{mg}$. three times daily to $2 \mathrm{mg}$. three times daily. If the patient becomes free of headache the dosage can then be lowered gradually to the minimum necessary to prevent attacks. No long-term sideeffect of methysergide was encountered in this trial. Indeed, we have encountered only two patients with a fibrotic syndrome in our experience with methysergide over the past seven years, which would now comprise about 1,000 patients. One patient developed typical retroperitoneal fibrosis and the other presented with pleuritic pain and was found to have chronic pleural thickening, which was biopsied at another hospital before the significance of methysergide treatment was appreciated.

Graham (1967) pointed out that retroperitoneal fibrosis, pleural fibrosis, and cardiac valvular fibrosis have been reported in only about 100 of the half-million patients who were estimated to have been treated with methysergide. The fibrotic complications of methysergide, which are reversible on ceasing medication, may well be the result of its serotonin-like action. Graham commented on the similarity of the appearance at operation of valvular fibrosis in methysergide-treated patients to that seen in carcinoid syndrome. The 
administration of serotonin to rats either decreases or increases granuloma formation, depending on the function of the adrenal gland (Bianchine and Eade, 1967). Excessive fibrosis appears only if adrenal insufficiency is induced. This raises the question of whether there might be adrenal insufficiency in patients who develop fibrotic syndromes in response to serotonin or methysergide. Possibly any drug which relies on a serotonin-simulating action for the treatment of migraine has the potential of producing excessive fibrosis in susceptible subjects.

We wish to thank Drs. J. D. Gillies and D. Burke and the neurological registrars who assisted us in the neurological clinic, and Miss A. M. Mackie and the staff of the pharmacy department for their willing collaboration. $\mathrm{BC105}$ and placebo tablets were supplied by Sandoz (Australia) Ltd., methdilazine by Mead Johnson Pty. Ltd., and Lysenyl (Spofa) by Boucher and Muir Pty. Ltd.

ADDENDUM.-BCl05 has now been given the generic name pizotifen and the proprietary name Sandomigran.

REFERENCES

Anthony, M., Hinterberger, H., and Lance, J. W. (1967). Archives of Neurology, 16, 544.

Anthony, M., Hinterberger, H., and Lance, J. W. (1969). In Research and Clinical Studies in Headache, vol. 2, edited by A. P. Friedman, p.29. Basel, Karger.
Anthony, M., and Lance, J. W. (1968). Medical fournal of Australia, 1, 56.

Bianchine, J. R., and Eade, N. R. (1967). Fournal of Experimental Medicine, 125, 501 .

Curran, D. A., Hinterberger, H., and Lance, J. W. (1965). Brain, 88, 997.

Curran, D. A., Hinterberger, H., and Lance, J. W. (1967). In Research and Clinical Studies in Headache, vol. 1, edited by A. P. Friedman, p.74. Basel, Karger.

Curran, D. A., and Lance, J. W. (1964). Fournal of Neurology, Neurosurgery and Psychiatry, 27, 463.

Dalessio, D. J., Camp, W. A., Goodell, H., and Wolff, H. G. (1961). Archives of Neurology, 4, 235.

De La Lande, I. S., Cannell, V. A., and Waterson, J. G. (1966). British fournal of Pharmacology and Chemotherapy, 28, 255.

Feher, P. H., and Kalz, F. (1966). Dermatologica. 133, 190.

Graham, J. R. (1967). American fournal of the Medical Sciences, 254, 23.

Graham, J. R. (1968). BC105 for prevention of migraine in patients previously taking methysergide. Headache Rounds, The Faulkner Hospital, 26 June.

Lance, J. W., and Anthony, M. (1968). Medical fournal of Australia, 1, 54.

Lance, J. W., Anthony, M., and Gonski, A. (1967). Archives of Neurology, 16, 553 .

Lish, P. M., Albert, J. R., Peters, E. L., and Allen, L. E. (1960). Archives Internationales de Pharmacodynamie et de Thérapie, 129,

Miller, J., and Fishman, A. (1961). Annals of Allergy, 19, 164.

Ryan, R. E. (1968). Headache, 8, 118.

Sicuteri, F. (1959). International Archives of Allergy and Applied Immunology, 15, 300.

Sicuteri, F., Franchi, G., and Del Bianco, P. L. (1967). International Archives of Allergy and Applied Immunology, 31, 78.

Sicuteri, F., Testi, A., and Anselmi, B. (1961). International Archives of Allergy and Applied Immunology, 19, 55.

\title{
Regional Lung Function in Patients with Obstructive Lung Diseases
}

\author{
DOMINIC GAZIANO,* ${ }^{*}$ M.D. ; ANTHONY SEATON, $†$ B.A., M.B., M.R.C.P. \\ COLIN OGILVIE, $\ddagger$ M.D., F.R.C.P.
}

British Medical fournal, 1970, 2, 330-333

\begin{abstract}
Ummary: Regional lung function was measured, using $\mathcal{~ r a d i o a c t i v e ~ x e n o n - 1 3 3 , ~ i n ~} a^{\prime}$ group of normal subjects and in three carefully defined groups of patients with obstructive lung disease. When compared with the normal subjects, patients in the emphysematous group showed a relative reduction of ventilation and perfusion to the upper zones, while patients having chronic bronchitis without cardiac or respiratory failure showed a predominantly lower zone defect. In the group of patients with chronic bronchitis with cardiac and respiratory failure no consistent pattern was found.
\end{abstract}

\section{Introduction}

Patients with obstructive lung diseases (chronic bronchitis or emphysema) have a wide range of abnormalities in regional lung function, but these have not been related to clinical or physiological types (Bentivoglio et al., 1963; Hugh-Jones et al., 1966; Pain et al., 1967). In most of these studies the disturbance of ventilation and perfusion was maximal in the lower parts of the lung. Conversely the morbid anatomical changes of both centrilobular and panacinar emphysema are predominant in the upper parts of the lung (Heard, 1959; Heppleston and Leopold, 1961). Earlier studies in this laboratory (Ogilvie and Catterall, 1959; Ogilvie, 1967) showed that bullae arising from the lower lobes were more often associated with chronic bronchitis, than those arising from the upper lobes. This evidence from previous published work suggested that regional abnormalities might be predominant in the lower parts of the lung in chronic bronchitis and in the upper parts in emphysema. In order to test this hypothesis we studied regional lung function with radioactive xenon-133 in three carefully

* Research Fellow from the University of West Virginia, Morgantown, U.S.A.

† Senior Medical Registrar.

$\ddagger$ Consultant Physician

Cardiothoracic Surgical Centre, Broadgreen Hospital, Liverpool 14 selected groups of patients with obstructive lung disorders, comparing the results with those obtained in normal subjects.

\section{Subjects}

The normal subjects were volunteers from among the hospital staff. None had any history of respiratory disease and all had normal chest radiographs. The patients all had physiological evidence of airways obstruction as defined by a forced expiratory volume in one second (F.E.V.1) of less than $60 \%$ of the forced vital capacity. They were divided into three groups: group 1, five patients with type $A$ or emphysematous obstructive lung disease; group 2, seven patients with type B or bronchitic obstructive lung disease associated with respiratory failure and cor pulmonale; and group 3, six patients with chronic bronchitis as defined by daily sputum production for more than three months of each year, but without respiratory failure or cor pulmonale.

The criteria for dividing the patients into type $\mathrm{A}$ and type B obstructive lung disease are essentially those of Fletcher et al., 1963, 1964. The criteria are listed in Table I, and the values for individual patients in each group are given in Table II. For admission to either group six of the seven criteria had to be fulfilled.

\begin{tabular}{|c|c|c|}
\hline & Type A & Type B \\
\hline 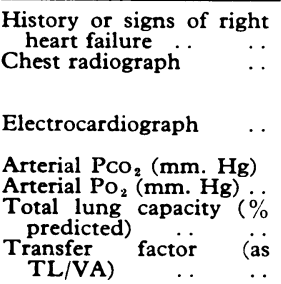 & $\begin{array}{l}\text { Absent } \\
\text { Normal heart size. } \\
\text { Peripheral vascular } \\
\text { attenuation } \\
\text { No right ventricular } \\
\text { hypertrophy } \\
\text { Under } 45 \\
\text { Over } 70 \\
\text { Over } 110 \% \\
\text { Under } 3.5\end{array}$ & $\begin{array}{l}\text { Present } \\
\text { Cardiac enlargement. In- } \\
\text { flammatory lung changes } \\
\text { only } \\
\text { Right ventricular hyper- } \\
\text { trophy } \\
\text { Over } 45 \\
\text { Under } 70 \\
\text { Under } 110 \% \\
\text { Over } 3.5\end{array}$ \\
\hline
\end{tabular}

